\title{
The importance of compassion and respectful care for the health workforce: a mixed-methods study
}

\author{
Kemal Jemal $^{1}$ (D) Dejene Hailu ${ }^{1} \cdot$ Mathewos Mekonnen $^{1} \cdot$ Bikila Tesfa $^{1} \cdot$ Kumera Bekele $^{1} \cdot$ Tadele Kinati $^{1}$
}

Received: 19 June 2020 / Accepted: 22 February 2021 / Published online: 11 March 2021

(C) The Author(s), under exclusive licence to Springer-Verlag GmbH Germany, part of Springer Nature 2021

\begin{abstract}
Background Compassionate and respectful care (CRC) is an essential element for health care providers (HCPs), which builds a positive environment and intimacy among health care professionals, patients, and families. However, there is a lack of studies examining the prevalence of and factors associated with compassionate and respectful care practice in low-resource countries. Therefore, this study aimed to assess the practice of compassionate and respectful care and its associated factors among the health workforce (HWF).

Methods This mixed-methods study was conducted through quantitative and qualitative data collection from April to May 2019 in North Shewa Zone health care facilities (NSHFs). For quantitative analysis, participants were selected using a systematic random sampling technique. Participants for qualitative analysis were selected using a purposive sampling technique. Data entries were made by EpiData version 3.2 and exported to SPSS version 23 software for analysis. Bivariable and multivariable logistic regression analyses were performed to determine the associated factors. Thematic analysis was carried out for qualitative data.

Results A total of 392 HWF responded to a self-administered survey, and 72 participants participated in focus group discussions (FGDs). Four categories of themes emerged: definition/knowledge, barriers, benefit, and leadership will. The prevalence of compassionate and respectful care practices was $38.8 \%$ and $46.2 \%$, respectively. Female gender, health officer role, having a monthly salary equal to or greater than 5000 Ethiopian birr, and a positive attitude were significantly associated with compassionate care practice. The age category of 30-39, positive attitude, and ensuring a safe and clean care environment were significantly associated with respectful care practice.

Conclusion Compassionate and respectful care among HWF requires an actual demonstration of humanity and kindness to promote person-centered practice for their clients. Therefore, the Ethiopian Federal Ministry of Health should emphasize CRC continuity by including it in the health care curriculum, improving the health care ethics skill gap, designing appropriate policy to reduce workload, and promoting patient rights.
\end{abstract}

Keywords Compassionate $\cdot$ Respectful $\cdot$ Caring $\cdot$ Health workforce $\cdot$ Ethiopia

\section{Background}

Compassionate and respectful care (CRC) is very important for human-centered care and serving patients ethically and

Kemal Jemal

olifanjemal@gmail.com

Dejene Hailu

dejenehailu77@yahoo.com

Mathewos Mekonnen

matemek2010@gmail.com

Bikila Tesfa

bikila2003@gmail.com with respect, adhering to a professional oath, and as a model for young professionals (Chapin et al. 2014; Shea and Lionis 2014; Chochinov 2007). It requires professional pride to address the patient's innate need (Larson 2014; Dewar et al.

Kumera Bekele

kumebek@gmail.com

Tadele Kinati

kinati2010@gmail.com

1 Department of Nursing, College of Health Sciences, Salale University, PO Box 245, Fitche, Ethiopia 
2014). In high-resource countries, CRC has gained attention as a significant source of flexibility and beneficial relationships, and as fundamental for human rights today (Mechili et al. 2018). Conversely, it is poorly demonstrated in lowresource countries (Berhe et al. 2017).

Compassion and respectful care is not optional, but the health workforce (HWF) is frequently seen as much less important than other aspects of care. A study in Canada found that compassion is broadly considered a cornerstone of quality health care improvement (Sinclair et al. 2018). In the UK, the role of compassion is more advanced in both health care settings and the homeless community (Goodrich 2016; Limebury and Shea 2015). A study conducted in the USA found that $64 \%$ of health care providers (HCPs) had experienced unkind behavior, failure to connect at a personal level $(38 \%)$, rudeness (36\%), and poor listening skills (35\%). More than three-fourths (87\%) of Americans prefer kind treatment by HCPs, and $90 \%$ of patients switch to kinder HCPs (Davis 2013).

A study conducted in the Tigray region of Ethiopia found that $44 \%$ of HCPs had a poor attitude toward CRC (Berhe et al. 2017). An aggregated 3-year report of the Addis Ababa Ethics Committee evaluated 60 complaints against HCPs; 39 complaints were related to a patient's death, and 15 complaints were about disability. More than one-fifth of the complaints represented an ethical breach or negligence. The use of bad language, shouting at patients, mistreatment, and insulting and hitting clients were some of the unethical practices shown by the HCPs (Wamisho et al. 2015). Similarly, a 7-year review of surgical and medical errors found that $57.6 \%$ of complaints documented in Ethiopia were related to death, and $21.6 \%$ involved bodily injury, ethical breach, and negligence (Wamisho et al. 2019). Another study from Addis Ababa found that one-fourth of medical doctors had no knowledgeable about the code of ethics, and 39\% had unfavorable attitudes toward the code of ethics (Tiruneh et al. 2019).

There are a variety of factors that may hinder compassionate and respectful care practices. They include compassion fatigue and burnout, emotional and physical exhaustion, diminished attentiveness and empathy, high workload and stressful health care environment, and lack of inspiration for HCPs (Haslam 2015; Maslach et al. 1986).

Providing CRC can aid in faster recovery from acute illness, enhance chronic disease management, and alleviate anxiety and tension (Davis 2013). Almost $85 \%$ of patients and $76 \%$ of HCPs agreed that compassionate care is necessary for successful medical outcomes (Lown et al. 2011). Emotional signs and the type of response by HWF may also be vital for the CRC, offering novel contributions to the therapeutic relationship and enhancing attitudes toward behavioral changes (Zimmermann et al. 2007; Chapin et al. 2014).
In Ethiopia, many professionals are compassionate and respectful of the required skills needed. However, a significant proportion of health care professionals see patients as cases and do not offer CRC for their patients and families (Shea et al. 2014). To address these gaps, the Ethiopian government has already established a CRC program and initiatives of health care services that are expanded beyond morbidity or mortality prevention. It must encompass respect for patients and fundamental human rights, including respect for patients' autonomy, dignity, feelings, preferences, and choice of friendship wherever possible. This quantitative and qualitative study provides insights to enable an advanced understanding of CRC practice. It identifies HWF behaviors associated with CRC that can contribute to future interventions to facilitate CRC implementation in low-resource health care settings. Therefore, we aimed to assess the practice of CRC and its associated factors among the HWF in North Shewa Zone Health Care Facilities.

\section{Methods}

\section{Study design, area, and period}

A mixed-methods study was carried out through quantitative and qualitative data collection from April to May 2019 in North Shewa Zone, Oromia Region. Quantitative data were gathered through a questionnaire administered to the HWF. Qualitative data were collected from key informants (HWF having a position in a health care facility) through focus group discussion to determine their understanding and/or insight regarding CRC services in health care facilities.

\section{Study participants}

The quantitative study participants were randomly determined using Epi Info version 7, with a 95\% confidence interval (CI) and a $5 \%$ margin of error. We assumed a prevalence of $56 \%$ based on a study done in the Tigray Region (Berhe et al. 2017). After adjusting for a non-response rate of 5\%, the final sample size was 398. Participants were randomly recruited from four hospitals and six health centers. The total sample size was allocated proportionally to each facility based on their number of HWF. The allocated number was in turn proportionally assigned to each department. A systematic sampling technique was used to select the HWF working in each selected department. All selected HWF who had been working for more than 6 months in the NSHFs were included. Those HWF who were on annual leave were excluded from the study.

For the qualitative study, focus group participants were recruited from four hospitals and two health centers. Seventy-two participants were selected from each department 
depending on their position and clinical experience, using a purposive sampling technique. We invited them to participate in scheduled focus groups through the invitation letter for volunteer key informants. A total of six FGDs were conducted, each containing 12 members; the number of participants was large, as the HWF was interested in participating in the FGDs.

\section{Data collection tools and procedure}

Quantitative data were collected using a standardized and pretested questionnaire. Data were collected by six diploma nurses and supervised by three BSc nurses. The questionnaire contains a sociodemographic query (age, sex, marital status, educational status, profession, years of experience, and monthly salary), CRC and health care ethics-related training, types of health care facilities (hospital or health center), awareness of policy and guidelines for CRC, knowledge about CRC, and attitude toward CRC.

The outcome of compassionate care was measured using a five-point Likert scale from 1 to 5 ( $1=$ almost never, $2=$ seldom, 3 = sometimes, 4 = often, $5=$ almost always). It contains six subscales (kindness, indifference, common humanity, separation, mindfulness, and disengagement) with a total of 24 question items. Indifference, separation, and disengagement were reversed to calculate a total compassion score. A total compassion score was calculated, each subscale's mean was taken, and a total mean was computed and considered a cutoff point. A score greater than the mean was considered good compassionate care practice, and less than the mean score was considered poor compassionate care practice (Pommier 2010).

The respectful care outcome was measured using a fivepoint Likert scale ( $1=$ almost never, $2=$ seldom, $3=$ sometimes, $4=$ often, $5=$ almost always), containing 21 items. The mean was computed, and the mean score was considered as a cutoff point. A score greater than the mean was considered respectful care practice, and less than the mean was considered poor respectful care practice (Reis et al. 2012).

The reliability of the compassionate and respectful care scale was pretested and found to be acceptable, with Cronbach's $\alpha=0.878$ and 0.856 , respectively, and the total sum of the CRC scales was Cronbach's $\alpha=0.907$ (Cronbach's $\alpha$ of CRC $=0.907$ ).

Knowledge was measured using eight questions, each with a "yes or no" response; each correct answer "yes" scored 1 point, and "no" scored 0. Again, attitude was measured by a five-point Likert scale ( 1 = strongly disagree, $2=$ disagree, $3=$ neither agree nor disagree, $4=$ agree, $5=$ strongly agree) using eight questions and dichotomized into disagree $(0)$ and agree (1). A score of 6 and above ( $>75 \%$ ) from eight questions was taken as a cutoff point for both knowledge and attitude. Greater than $75 \%$ were considered knowledgeable and a positive attitude and less than $75 \%$ were poor knowledge and negative attitude toward CRC.

In a qualitative study, FGDs were conducted at Fitche General Hospital, Kuyu General Hospital, Muka Turi Primary Hospital, Gundomaskel Primary Hospital, Wara Jarso Health Center, and Debratsige Health Center. Data were collected through guiding questions in both Amharic and Afan Oromo languages. A semi-structured interview guide was developed to elicit an advanced understanding of the value or benefit and knowledge of CRC, and behaviors associated with CRC. During FGDs, one moderator and reporter were present for each FGD and audio-recording during the discussion for an average of $2 \mathrm{~h}$.

\section{Data processing and analysis}

Quantitative data were coded, edited, cleaned, and entered into EpiData version 3.2 and then exported to SPSS version 23. Descriptive data analysis was carried out and presented in frequency, percentage, tables, and graphs. Analysis was performed with an odds ratio with $95 \%$ confidence interval, and a two-tailed $P$ value was calculated to identify the presence and strength of association. Variables with a $p$ value $\leq 0.2$ in the binary analysis were included in a multivariable logistic regression analysis to control the confounding variables. A value of $p<0.05$ was considered indicative of statistical significance.

The qualitative data were transcribed and translated from both Amharic and Afan Oromo to English. The verbatim transcripts were separately verified against the audio recorded by the interviewer and a member of the analysis team. The analysis team further guaranteed the consistency of each focus group and interview session. The teams also analyzed the interviewer's adherence to each transcript's probing questions and provided feedback and correction. They read through each transcript again to reduce differences between individual codes and mark out parts of the transcript that were nonspecific to CRC through a consensus process. Rigor was further ensured by the study team, who was not involved in analyzing the interviews or focus groups, and independently audited the coding process. Finally, the narrative was organized and integrated according to emerging themes and concepts set out in the research objectives, and the result was triangulated with quantitative findings at the interpretation level.

\section{Ethical consideration}

Ethical clearance was obtained from the Salale University Ethical Review Committee (Ref. No. SLUERC/32/2019, on March 18, 2019). Written permission was obtained from the North Shewa Zone Health Bureau (NSZHB), and written informed consent was obtained from each respondent. The 
respondents were informed that their inclusion in the study was voluntary and that they are free to withdraw from the study if they were not willing to participate. To ensure respondents' confidentiality, their names were excluded from the questionnaire, and the respondents' anonymity was maintained.

\section{Results}

\section{Quantitative findings}

In this study, a total of 392 individuals participated, with a response rate of $98.5 \%$. More than half of the participants were from the hospitals. The study respondents' mean age was 28.42 ( \pm standard deviation $=5.17$ ), and two-thirds were aged 20-29 years. Most of the study participants were male $(52.3 \%)$, single $(52.6 \%)$, and had a bachelor's degree $(52.8 \%)$. Nurses $(194 ; 49.5 \%)$ constituted the majority of the HWF, and 208 (53.1\%) of the respondents had less than 5 years of experience. More than half $(207 ; 52.8 \%)$ of the study participants earned a monthly salary of less than 5000 Ethiopian birr (Table 1).

The majority of records officers $(79.1 \%)$ facilitated patient registration in a timely manner, and $72.4 \%$ of participants treated patients and families respectfully. Eighty percent of the facilities ensured a safe and clean care environment for the patients, and $32.1 \%$ of the facilities detained patients against their will. Most of the HWF had good knowledge of CRC (62.8\%), greeted the client respectfully $(89.3 \%)$, and had a negative attitude toward CRC (52.6\%). Nearly three-fifths of leaders empowered patients and employees positively (Table 2).

\section{The practice of compassionate and respectful care}

The full scale of compassion contains six subscales, including kindness, indifference, common humanity, separation, mindfulness, and disengagement. The majority (224; $57.1 \%$ ) of the respondents reported poor kindness while $168(42.9 \%)$ reported good kindness for their patients. Half (198; 50.5\%) of the study participants had high indifference, and 194 (49.5\%) had low indifference. More than half (51\%) of the study participants had poor common humanity and mindfulness, and 49\% did not. About 214 (54.6\%) and 204 (52\%) of the respondents had poor separation and disengagement, respectively (Fig. 1).

The overall compassionate care among the HWF was reported as $38.8 \%$ of good compassionate care practices, and $240(61.2 \%)$ of the HWF reported poor compassionate care practice. On the other hand, 181(46.2\%) of the study participants reported good respectful care practices, and $53.8 \%$ of
Table 1 Sociodemographic factors among HWF at North Shewa health facilities, Oromiya Region, Ethiopia, $2019(n=392)$

\begin{tabular}{|c|c|c|}
\hline Variable & Number of participants & Percentage \\
\hline \multicolumn{3}{|l|}{ Age (years) } \\
\hline $20-29$ & 261 & 66.6 \\
\hline $30-39$ & 117 & 29.8 \\
\hline$\geq 40$ & 14 & 3.6 \\
\hline \multicolumn{3}{|l|}{ Sex } \\
\hline Male & 205 & 52.3 \\
\hline Female & 187 & 47.7 \\
\hline \multicolumn{3}{|l|}{ Marital status } \\
\hline Single & 206 & 52.6 \\
\hline Married & 186 & 47.4 \\
\hline \multicolumn{3}{|l|}{ Health facility } \\
\hline Hospital & 204 & 52.0 \\
\hline Health center & 188 & 48.0 \\
\hline \multicolumn{3}{|l|}{ Educational status } \\
\hline Diploma & 175 & 44.6 \\
\hline $\mathrm{BSc} / \mathrm{MD}$ & 207 & 52.8 \\
\hline $\mathrm{MSc} /$ specialty & 10 & 2.6 \\
\hline \multicolumn{3}{|l|}{ Profession } \\
\hline Nurse & 194 & 49.4 \\
\hline & 20 & 5.1 \\
\hline \multicolumn{3}{|l|}{$\begin{array}{l}\text { Physician/- } \\
\text { MD }\end{array}$} \\
\hline Midwife & 70 & 17.9 \\
\hline MLS & 32 & 8.2 \\
\hline Pharmacist & 26 & 6.6 \\
\hline Health officer & 40 & 10.2 \\
\hline Other $^{\mathrm{a}}$ & 10 & 2.6 \\
\hline \multicolumn{3}{|c|}{ Years of experience } \\
\hline$<5$ years & 208 & 53.1 \\
\hline$\geq 5$ years & 184 & 46.9 \\
\hline \multicolumn{3}{|l|}{ Monthly salary } \\
\hline$<5000$ & 207 & 52.8 \\
\hline$\geq 5000$ & 185 & 47.2 \\
\hline
\end{tabular}

${ }^{\text {a }}$ Others: anesthetists, guardians, and radiographers

the respondents reported poor respectful care practices (Fig. 2).

\section{Factors associated with compassionate and respectful care}

In multivariable logistic regression analysis, the age category of 30-39 and married participants were adjusted for compassionate care practice (Table 3). Similarly, female participants, HWF who had a bachelor's degree and good knowledge of respectful care were adjusted in multivariable logistic regression analysis for respectful care practice (Table 4). 
Table 2 Important variables related to compassionate and respectful care among HWF at NSHFs, Oromia region, Ethiopia, $2019(n=392)$

\begin{tabular}{lcc}
\hline \multicolumn{2}{c}{ Variables } & Percentage \\
\hline Records officers facilitate patient registration on time & \\
Yes & 310 & 79.1 \\
No & 82 & 20.9 \\
The facility detains patients without their will & \\
Yes & 126 & 32.1 \\
No & 266 & 67.9 \\
The facility ensures a safe and clean care environment for patients \\
Yes & 314 & 80.1 \\
No & 78 & 19.9 \\
The guards receive patients and families with respect & \\
Yes & 316 & 80.6 \\
No & 76 & 19.4 \\
The records officers treat patient and families with respect & \\
Yes $\quad 284$ & 72.4 \\
No & 108 & 27.6 \\
Do you greet the client respectfully & \\
Yes & 350 & 89.3 \\
No & 42 & 10.7 \\
Leaders influence the patient, client, and employee positively & \\
Yes & 242 & 61.7 \\
No & 150 & 38.3 \\
Attitude toward compassionate and respectful care & \\
Positive attitude & 186 & 47.4 \\
Negative attitude & 206 & 52.6 \\
Knowledge of compassionate and respectful care & \\
Good knowledge & 246 & 62.8 \\
Poor knowledge & 146 & 37.2 \\
\hline
\end{tabular}

In multivariable logistic regression analysis, female participants were twice as likely to practice compassion as male participants $[\mathrm{AOR}=1.95 ; 95 \% \mathrm{CI}=(1.40,3.64)]$. Health officers had significantly higher odds of providing good compassionate care practice than nurses $[\mathrm{AOR}=3.61,95 \%$ $\mathrm{CI}=(1.56,8.34)]$. The study participants who had a monthly salary equal to or greater than 5000 Ethiopian birr were twice as likely to practice compassionate care as those who whose monthly salary was less than 5000 Ethiopian birr [AOR = $1.56 ; 95 \% \mathrm{CI}=(1.13,3.29)]$. The study participants who had a positive attitude toward compassionate care were 1.23 times as likely to practice compassion as the study participants with a negative attitude toward compassion $[\mathrm{AOR}=1.23$; $95 \% \mathrm{CI}=(1.24,3.72)]$ (Table 3$)$.

The study participants in the 30-39 age category were twice as respectful as those aged 20-29 [AOR $=1.80 ; 95 \%$ $\mathrm{CI}=(1.24,3.84)]$. The study participants who had a positive attitude toward respectful care were 1.59 times as likely to practice respectful care as those who had a negative attitude toward respectful care practice $[\mathrm{AOR}=1.59 ; 95 \% \mathrm{CI}=(1.02$, 2.50)]. The study participants who had ensured safe and clean care for their patients were three times as likely to practice respectful care as the study participants who did not $[\mathrm{AOR}=3.39,95 \% \mathrm{CI}=(2.31,8.35)($ Table 4$)$.

\section{Qualitative findings}

A qualitative approach was applied to explore compassionate and respectful care not addressed by the quantitative study. We developed an understanding of the topic through concurrent data collection from 72 participants in six FGDs. The collected data were analyzed, and four categories of themes emerged: definition/knowledge of CRC, CRC barriers, the benefit of CRC, and leadership will.

\section{Definition and knowledge of CRC}

The participants provided the knowledge and definition of CRC as fundamental for health care workers. It is a part of psychotherapy that has no negative effect and increases patient satisfaction and care provision. Most of the participants described the meaning of CRC as:

$C R C$ is the psychological and medical supporting of the patients. Improving from pain or suffering regardless of their economic status, culture, religion, and ethnicity. (FGD5 participant 6)
Fig. 1 The prevalence of compassionate care subscales among HWF at NSHFs, Oromia region, Ethiopia, $2019(n=392)$

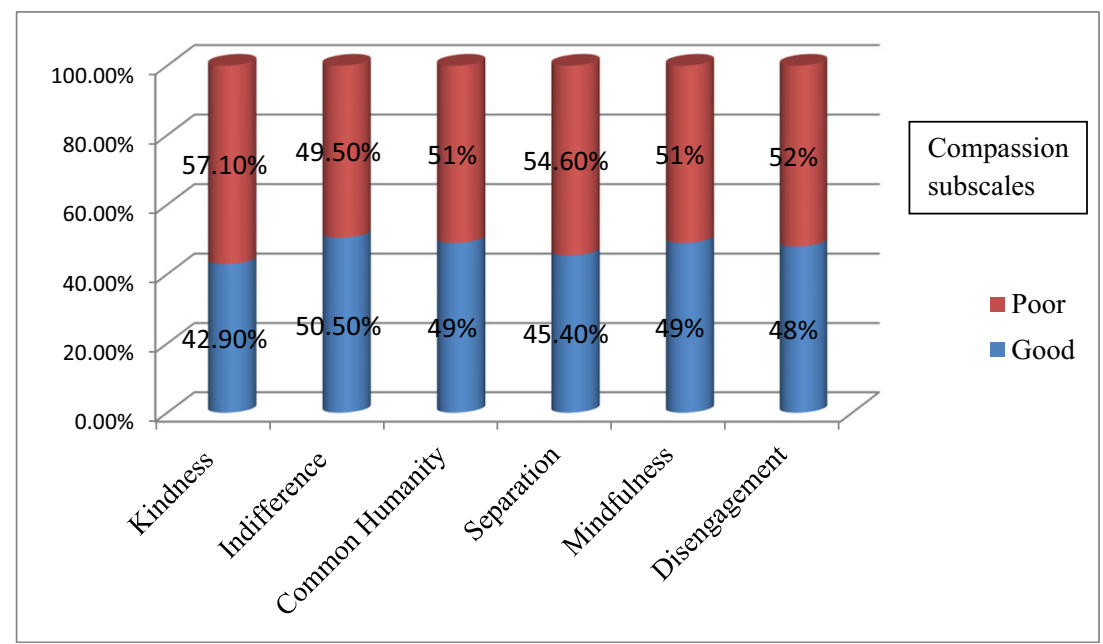


Fig. 2 The prevalence of compassionate and respectful care practices among HWF at NSHFs, Oromia region, Ethiopia, 2019 $(n=392)$

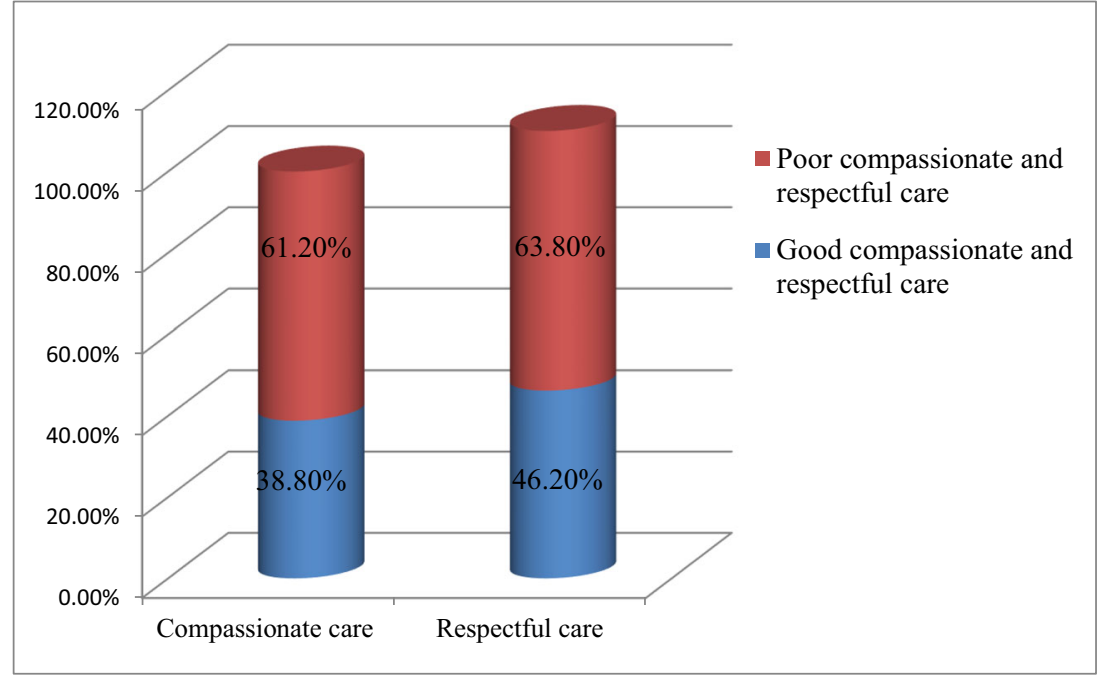

Knowing the patient's rights and responsibilities is mandatory to provide the correct care for clients. The CRC has three criteria: first, our clients come to our health care system to heal me; second, if you can't heal me, respect me, and third, if you can't respect me, don't harm me. (FGD3 participant 1)

The majority of FGDs claimed that CRC is a deep sense to alleviate clients suffering, empathy, sharing their pain, developing the inner feelings to build relationships. It is more kindness for human beings rather than clinician to patient relationship. It also includes honesty, attention, never stereotypes; demonstrate humanity and kindness to promote high-quality care for all clients' needs. (FGD5 participant 1)

Compassion and respectful care is sharing one's pain or suffering and responding with respectful behavior to the client's suffering. (FGD2 participant 3)

If CRC is initiated in the health care facilities, with the attitudes of empathy, caring, kindness, and respect, it creates meaningful partnerships between HCPs and patients or families. It is a motivating feeling of HCPs that makes the patient feel relief from suffering. (FGD6 participant 4)

\section{Barriers to $\mathrm{CRC}$}

The barriers to $\mathrm{CRC}$ have inhibited the ability to provide daily routine activities. Health care professionals faced countless challenges that hinder their ability to provide CRC. It includes lack of integration and continuity care, technologies that help and hinder communication and relationship-building, growing operational and administrative supplies, insufficient communication skills training, alarming burnout rates, and increased cost and limited market resources. The focus group discussion reflected that the unorganized health care administration, skill gap, autocracy, and professional dissatisfaction are the main obstacles for the CRC practice.

There is a Hippocrates quote, "Wherever the art of medicine is loved, there is also a love of humanity." Mostly, the person who wants to be a health care professional is a person that loves human beings. However, due to the high workload, language barrier, attendant attitude, medical supply, cultural views, and lack of incentive, HCPs may be restricted in the provision of CRC practice. (FGD4 participant 8)

Unorganized administration, shortage of training, lack of joy in his/her profession, and HCPs' dissatisfaction are the main obstacles for CRC practice. (FGD6 participant 9) There are communication difficulties and patient load, and HWF do not explain more health information. Similarly, lack of good relationships, resource shortage, ignorance, the autocracy of a few HCPs, deficiency of knowledge, and skill gap are among the barriers preventing CRC implementation. (FGD1 participant 12)

\section{Benefit of CRC:}

The HWF believed that CRC is one of the most important professional values. However, it is determined by HWF values, in which protection, honor, honesty, respect, and trust are key values in CRC. The FGDs argued that the provision of $\mathrm{CRC}$, maintaining the code of ethics, better counseling, and a respectful approach is useful for patients and HCPs. Some HWF had an active form of articulating CRC, while other individuals used more restricted behaviors such as maintaining serenity, reluctance to clients, inquiry, and being present only. 
Table 3 Factors (crude and adjusted odds ratios, confidence intervals, and $p$ value) associated with compassionate care among HWF at NSHFs, Oromia region, Ethiopia, $2019(n=392)$

\begin{tabular}{|c|c|c|c|c|c|c|}
\hline \multirow[t]{2}{*}{ Variables } & \multicolumn{2}{|c|}{ Compassion care } & \multirow[t]{2}{*}{ Crude OR (95\% CI) } & \multirow[t]{2}{*}{$p$ value } & \multirow[t]{2}{*}{ Adjusted OR (95\% CI) } & \multirow[t]{2}{*}{$p$ value } \\
\hline & Poor & Good & & & & \\
\hline \multicolumn{7}{|l|}{ Age } \\
\hline $20-29$ & 151 & 110 & 1 & & 1 & \\
\hline $30-39$ & 81 & 36 & $0.61(0.38,0.97)$ & $0.037 *$ & $0.53(0.36,1.14)$ & 0.133 \\
\hline$\geq 40$ & 8 & 6 & $1.03(0.35,3.05)$ & 0.958 & $0.83(0.42,4.93)$ & 0.568 \\
\hline \multicolumn{7}{|l|}{ Sex } \\
\hline Male & 109 & 96 & 1 & & 1 & \\
\hline Female & 131 & 56 & $2.06(1.36,3.12)$ & $0.001 *$ & $1.95(1.40,3.64)$ & $0.001 *$ \\
\hline \multicolumn{7}{|l|}{ Marital status } \\
\hline Single & 114 & 92 & 1 & & 1 & \\
\hline Married & 126 & 60 & $1.70(1.12,2.56)$ & $0.012 *$ & $1.43(0.86,2.38)$ & 0.170 \\
\hline \multicolumn{7}{|l|}{ Profession } \\
\hline Nurse & 130 & 64 & 1 & & 1 & \\
\hline Physician/MD & 12 & 8 & $1.35(0.53,3.48)$ & 0.529 & $1.16(0.38,3.51)$ & 0.798 \\
\hline Midwife & 44 & 26 & $1.20(0.68,2.12)$ & 0.530 & $1.12(0.58,2.16)$ & 0.742 \\
\hline MLS & 18 & 14 & $1.58(0.74,3.38)$ & 0.238 & $1.19(0.46,3.07)$ & 0.727 \\
\hline Pharmacist & 14 & 12 & $1.74(0.76,3.98)$ & 0.189 & $1.67(0.58,4.75)$ & 0.340 \\
\hline Health officer & 14 & 26 & $3.77(1.85,7.71)$ & $0.001 *$ & $3.61(1.56,8.34)$ & $0.003 *$ \\
\hline Others $^{\mathrm{a}}$ & 8 & 2 & $0.50(0.11,2.46)$ & 0.400 & $0.33(0.06,1.81)$ & 0.201 \\
\hline \multicolumn{7}{|l|}{ Educational status } \\
\hline Diploma & 113 & 62 & 1 & & 1 & \\
\hline $\mathrm{BSC} / \mathrm{MD}$ & 121 & 86 & $1.30(0.86,1.96)$ & 0.222 & $0.61(0.36,1.06)$ & 0.080 \\
\hline MSC/MPH/Specialty & 6 & 4 & $1.22(0.33,4.47)$ & 0.769 & $0.92(0.20,4.20)$ & 0.919 \\
\hline \multicolumn{7}{|l|}{ Monthly salary } \\
\hline$<5000$ & 141 & 66 & 1 & & 1 & \\
\hline$\geq 5000$ & 99 & 86 & $1.86(1.23,2.80)$ & $0.003 *$ & $1.56(1.13,3.29)$ & $0.016^{*}$ \\
\hline \multicolumn{7}{|l|}{ Years of experience } \\
\hline$<5$ years & 122 & 86 & 1 & & 1 & \\
\hline$\geq 5$ years & 118 & 66 & $1.26(0.84,1.90)$ & 0.267 & $1.03(0.60,1.74)$ & 0.926 \\
\hline \multicolumn{7}{|c|}{ Attitude toward compassion } \\
\hline Negative attitude & 138 & 68 & 1 & & 1 & \\
\hline Positive attitude & 102 & 84 & $1.67(1.11,2.52)$ & $0.014 *$ & $1.23(1.24,3.72)$ & $0.002 *$ \\
\hline \multicolumn{7}{|c|}{ Knowledge of compassion } \\
\hline Poor knowledge & 92 & 54 & 1 & & 1 & \\
\hline Good knowledge & 148 & 98 & $1.13(0.74,1.72)$ & 0.575 & $0.92(0.87,2.32)$ & 0.165 \\
\hline \multicolumn{7}{|c|}{ Ensures safe and clean care } \\
\hline No & 54 & 24 & 1 & & 1 & \\
\hline Yes & 186 & 128 & $1.55(0.91,2.63)$ & 0.107 & $1.42(0.78,2.59)$ & 0.247 \\
\hline
\end{tabular}

${ }^{a}$ Others: anesthetists, guardians, and radiographers. ${ }^{*} p<0.05$ (considered significantly associated in bivariable and multivariable logistic regression)

Suppose we use CRC correctly in our daily activities. In that case, it minimizes medication adherence or compliance issues, improves health care professionals' burnout, increases loyalty and respect for the clients, and relieves pain and distress. In addition to health ethics, CRC orientation is essential. It is not only learned but needs updated training and psychological advice to adhered health care service. (FGD6 participant 1)

In low-resource settings, the community comes to health care facilities after they are deteriorating; they need psychological, social, compassion, 
Table 4 Factors (crude and adjusted odds ratios, confidence intervals, and $p$ value) associated with respectful care among HWF at NSHFs, Oromia region, Ethiopia, 2019(n=392)

\begin{tabular}{|c|c|c|c|c|c|c|}
\hline \multirow[t]{2}{*}{ Variable } & \multicolumn{2}{|c|}{ Respectful care } & \multirow[t]{2}{*}{ Crude OR (95\% CI) } & \multirow[t]{2}{*}{$p$ value } & \multirow[t]{2}{*}{ Adjusted OR (95\% CI) } & \multirow[t]{2}{*}{$p$ value } \\
\hline & Poor & Good & & & & \\
\hline \multicolumn{7}{|l|}{ Age (years) } \\
\hline $20-29$ & 155 & 106 & 1 & & 1 & \\
\hline $30-39$ & 50 & 67 & $1.96(1.26,3.05)$ & $0.003 *$ & $1.80(1.24,3.84)$ & $0.007^{*}$ \\
\hline$\geq 40$ & 6 & 8 & $1.95(0.66,5.78)$ & 0.229 & $1.81(0.55,6.00)$ & 0.333 \\
\hline \multicolumn{7}{|l|}{ Sex } \\
\hline Male & 121 & 84 & 1 & & 1 & \\
\hline Female & 90 & 97 & $1.55(1.04,2.32)$ & $0.031^{*}$ & $1.34(0.83,2.18)$ & 0.237 \\
\hline \multicolumn{7}{|l|}{ Marital status } \\
\hline Single & 114 & 92 & $0.75(0.50,1.11)$ & 0.149 & $0.68(0.62,1.73)$ & 0.911 \\
\hline Married & 126 & 60 & 1 & & 1 & \\
\hline \multicolumn{7}{|l|}{ Profession } \\
\hline Nurse & 101 & 93 & 1 & & 1 & \\
\hline Physician/MD & 10 & 10 & $1.09(0.43,2.73)$ & 0.861 & $0.97(0.40,4.00)$ & 0.684 \\
\hline Midwife & 30 & 40 & $1.45(0.84,2.51)$ & 0.188 & $1.20(0.94,3.45)$ & 0.077 \\
\hline MLS & 18 & 14 & $0.85(0.40,1.79)$ & 0.660 & $0.76(0.31,1.87)$ & 0.551 \\
\hline Pharmacist & 18 & 8 & $0.48(0.20,1.16)$ & 0.104 & $0.35(0.22,2.00)$ & 0.432 \\
\hline Health officer & 26 & 14 & $0.59(0.29,1.19)$ & 0.138 & $0.43(0.61,3.35)$ & 0.417 \\
\hline Other $^{\mathrm{a}}$ & 8 & 2 & $0.27(0.06,1.31)$ & 0.105 & $0.22(0.12,4.35)$ & 0.723 \\
\hline \multicolumn{7}{|l|}{ Educational status } \\
\hline Diploma & 85 & 90 & 1 & & 1 & \\
\hline $\mathrm{BSC} / \mathrm{MD}$ & 122 & 85 & $0.66(0.44,0.99)$ & $0.043 *$ & $0.50(0.42,1.21)$ & 0.204 \\
\hline MSC/MPH/Specialty & 4 & 6 & $1.42(0.39,5.20)$ & 0.599 & $0.92(0.18,4.75)$ & 0.921 \\
\hline \multicolumn{7}{|l|}{ Monthly salary } \\
\hline$<5000$ & 111 & 96 & 1 & & 1 & \\
\hline$\geq 5000$ & 100 & 85 & $0.98(0.66,1.46)$ & 0.932 & $0.95(0.55,1.62)$ & 0.840 \\
\hline \multicolumn{7}{|l|}{ Years of experience } \\
\hline$<5$ years & 118 & 90 & 1 & & 1 & \\
\hline$\geq 5$ years & 93 & 91 & $1.28(0.86,1.91)$ & 0.220 & $1.15(0.81,2.29)$ & 0.247 \\
\hline \multicolumn{7}{|c|}{ Attitude toward compassion } \\
\hline Negative attitude & 123 & 83 & 1 & & 1 & \\
\hline Positive attitude & 88 & 98 & $1.65(1.11,2.46)$ & $0.014 *$ & $1.59(1.02,2.50)$ & $0.043^{*}$ \\
\hline \multicolumn{7}{|l|}{ Knowledge of compassion } \\
\hline Poor knowledge & 92 & 54 & 1 & & 1 & \\
\hline Good knowledge & 119 & 127 & $1.82(1.20,2.76)$ & $0.005^{*}$ & $1.59(0.98,2.56)$ & 0.056 \\
\hline \multicolumn{7}{|c|}{ Ensures safe and clean care } \\
\hline No & 62 & 16 & 1 & & 1 & \\
\hline Yes & 149 & 165 & $4.29(2.37,7.76)$ & $0.001 *$ & $3.39(2.31,8.35)$ & $0.001^{*}$ \\
\hline
\end{tabular}

${ }^{\text {a }}$ Other: anesthetists, guardians, and radiographers. ${ }^{*} p<0.05$ (considered significantly associated in bivariable and multivariable logistic regression)

counseling, and treatment with respectful care. (FGD2 participant 5)

If the HWF advanced CRC, both patients and HCPS would be satisfied. The quality and utilization of health care facilities are increased. (FGD participant 10)

4. Leadership will:

Leadership is essential for enabling the workplace environment and continuing $\mathrm{CRC}$ in health care facilities. Participants noted that compassionate leadership starts to see and feel what others see and feel around health care facilities. (FGD6 participant 7)

An understanding and respectful leader puts himself with the other person's idea, view, and honor, with a respectful approach. Most of the leaders only slightly demonstrated actual CRC; they put political commitments first, and some could not show real compassion. (FGD1 participant 12)

The FGDs described multifaceted health care facilities in lowresource settings as having several challenges arising from client feelings, expressions of emotion, scarcity of resources, health care physical problems, and shortage of trained and compassionate leaders. The participants also described their experience in health care settings. 
The biggest problem in a health care setting is the presence of uncompassionate and disrespectful leaders. Leaders may not take the positive reward, not share the ability to solve the problems rather than criticizing and following a higher level of punishment. (FGD2 participant 1)

Health care systems need well-organized leaders, good governance, administrators, and HWF who practice CRC to improve patient suffering. There is a weakness of follow-up in health care service management to minimize shortages of compassionate leadership, starting from the health care bureau. (FGD5 participant 11) I was a leader 2 years ago; there is a complicated clinical situation, individual behaviors, patient, and family concerns. The leader should maintain all factors and be responsible for positively responding and managing their moods that develop good communication and relationships. (FGD3 participant 2)

\section{Discussion}

Compassionate and respectful care is human-centered and enhances high-quality care and better health care-seeking behaviors. Our qualitative analysis showed that CRC is " $a$ deep sense to alleviate clients' suffering, empathy, sharing their pain, developing the inner senses" to address patients' core needs. A previous study indicated that respect for clients, family, and visitors is a fundamental human right, including respect for autonomy, dignity, feelings, choices, and health care preferences (Gallagher et al. 2008). Similarly, from the view of FGDs, CRC is not only an approach to patients; it is "more a kindness for human beings," not only relationships between HCPs and patients or families. A study found that a client's ethnicity, religion, beliefs, culture, language, age, gender, disability, mental status, and social conditions should be considered when assessing, examining, diagnosing, planning, and managing any health condition (Anderson et al. 2003).

In this study, we found a benefit of CRC in the qualitative components, in that the presence of CRC "improves health care professionals' burnout, increases loyalty and respect for the clients," which leads to a meaningful and satisfying working environment. Various studies have revealed that the presence of compassionate and respectful health professionals leads to less anxiety and fewer complaints among patients, better adherence to medical advice and treatment plans, reduced malpractice, accelerated healing processes, better relationships between clinician and clients, and improved health care quality (De Silva 2014; Goodrich 2016).

The present study found that the proportion of good compassionate care practice was $38.8 \%$. This finding is in line with the study findings in the United States in which $36 \%$ of
HCPs demonstrated kinder behavior in health care facilities (Davis 2013). On the other hand, $46.2 \%$ of the study participants reported good respectful care practice. This result is lower than the study reported in the Tigray region, Ethiopia, in which $56 \%$ of the respondents had good practice of CRC (Berhe et al. 2017). This difference may be explained by the settings, tools, and methodology used in the studies.

The quantitative analysis showed that $61.7 \%$ of leaders empowered their patients, clients, and employee positively. Compassionate and respectful leadership is more than just being compassionate, respectful, and caring individuals. It needs individual commitment, honorable models of leadership, sharing of their views, and corrective direction. The qualitative study findings also found that leadership is a key element in advancing CRC in health care facilities. The participants noted that "the leader should maintain all factors and be responsible for positively responding and managing their moods that develop good communication and relationships" to handle the complicated health care environment. Most complex health care systems have been presented in resource-limited countries; leadership had not adapted to this practice and shared it among their employees and clients (Boal and Schultz 2007). Compassionate leadership encourages employees to discuss their problems, provides support, and manages complex health care systems by empowering all HWF (Gilbert et al. 2012).

With increasing age, the responsibility for caring for the patient and capacity for problem-solving are also increased. We found that the 30-39 age category was significantly associated with respectful care practice compared to the 20-29 age category. HCPs were more respectful at young adulthood, demonstrating more meaningful long-term relationships and academic and career decisions (Larson 2000; Stewart 1995). During young adulthood, the HWF was more respectful of their clients and clients' families through better health care provision.

In this study, we found that female participants were more compassionate than male participants, which was similar to findings of a US study that revealed female participants were more compassionate and honest than male participants (Kahn 1992). Studies found that females could exhibit caring behavior and show better feeling for patients, and were more sympathetic than males, enhancing emotional well-being with positive effects (Bluth and Blanton 2015). A similar study found that females were more responsible for caring and cooperating with others, having a good attitude toward patient care and good professional behaviors (Kleinman et al. 1978).

Health officers were significantly associated with better compassionate care when compared to nurses. This might be due to curriculum differences and clinical care among HCPs. Some health care professional curriculums at schools have integrated caring and compassion in parallel throughout undergraduate education and teach medico-legal ethics and how 
to demonstrate $\mathrm{CRC}$ at the bedside beyond their professional roles (Blanco et al. 2013; Graber et al. 2012). Similarly, some medical schools have offered longitudinal experiences in which students participated in patients' care over time and develop relationships with the clinicians who care for their patients. These health care professionals perceived more positive role-modeling than other health care professionals in conventional clinical learning experiences (Davis et al. 1999).

We found that the study participants who had a monthly salary greater than or equal to 5000 Ethiopian Birr were more compassionate than those with monthly salaries of less than 5000 Ethiopian Birr. The HWF who have low monthly salary might have low compassion, which is supported by qualitative findings. The participant noted that "lack of incentive for health care providers may be a restricted provision of CRC practice" under the sub-theme of barriers. Compassionate care is an essential part of quality health care; due to system fragment and HWF compassion fatigue, the unmet client needs alarm health care dissatisfaction and poor quality of care (Sinclair et al. 2018).

In this study, those HWF with a positive attitude toward $\mathrm{CRC}$ were significantly associated with compassionate and respectful care practice. This finding is in line with the study done in Canada (Dyrbye and Shanafelt 2011). Additionally, it is supported by qualitative findings while health care professionals develop "the attitude of empathy, caring, kindness, and respect" in the health care facilities, HWF could be made a meaningful relationship with patients and families. Thus, the ability to sustain CRC absolutely in the health care settings is rested in the HCPs' hands (Goodrich 2016).

In our study, those members of the HWF who ensured a safe and clean care environment for the patients were significantly associated with good practice of respectful care. Qualitative findings support this, stated as health care systems need well-organized leaders, good governance, administrators, and HWF who practice CRC to minimize patient complaints and suffering. A study found that health care organizations might remove the barriers that prevent clinicians from interacting directly with patients and improve the continuity of better health care services (Berwick 2009). Other studies found that health care settings might be responsive to the emotional, social, cultural, and linguistic needs of the patients and families served in the health care facilities (Epstein et al. 2010; Wise et al. 2011).

\section{Limitations of the study}

Although our study utilized quantitative and qualitative analysis and a saturated number of qualitative participants, with the quantitative study's pertinent findings to strengthen it, it does not show a causal relationship due to its cross-sectional. The study has been conducted at health care facilities located in North Shewa Zone of Oromiya Region. Therefore, our findings cannot be generalizable to the other regions of Ethiopia HWF.

\section{Conclusion}

Compassionate and respectful care among HWF requires an actual demonstration of humanity and kindness to promote person-centered practice for their clients. In fact, its absence leads to negligence and malpractice. Both quantitative and qualitative findings indicated that CRC provides an important benefit. Those life events that are seen to lead to burnout and exhaustion for the HWF should be reduced to make CRC progress possible. The client's wish is to be comforted and treated as a human being. Empowering patient decisions should be transformed from the apparent perverse to rational desire. Therefore, the Ethiopian Federal Ministry of Health should emphasize CRC continuity by including it in the health care curriculum, closing the health care ethics skill gap, designing appropriate policy to reduce workload, and promoting patient rights.

Abbreviations CRC, Compassionate and respectful care; FGDs, Focus group discussions; HWF, Health workforce; HCFs, Health care facilities; HCPs, Health care providers; NSHFs, North Shewa Health facilities; NSZHB, North Shewa Zone Health Bureau; SLU, Salale University; SPSS, Statistical Package for the Social Sciences; UK, United Kingdom; USA, United States of America

Acknowledgements We acknowledge Salale University for funding this research and all HWF in North Shewa health care facilities, who gave us necessary data for this research to be realized.

Authors' contributions Kemal Jemal was involved in the study conception and design, article review, analysis, report writing, and drafting of the manuscript. Dejene Hailu, Mathewos Mekonnen, Bikila Tesfa, Kumera Bekele, and Tadele Kinati were involved in the study design, article review, analysis, and report writing. All authors read and approved the manuscript.

Funding This research work is funded by Salale University (SLU). The funders had no role in the study design, data collection and analysis, decision to publish, or preparation of the manuscript.

Data availability The data for this study can be made available from the corresponding author on reasonable request.

\section{Declarations}

Conflict of interest The authors declare that they have no conflict of interest.

Ethical approval All procedures performed in studies involving human participants were in accordance with the institutional and/or national research committee's ethical standards and with the 1964 Helsinki Declaration and its later amendments or comparable ethical standards. 
The study was approved by the Salale University Ethical Review Committee (Ref. No. SLUERC/32/2019, on March 18/2019).

Informed consent Written informed consent was obtained from each respondent. The respondents were informed that their inclusion in the study was voluntary, and that they were free to withdraw from the study if they were not willing to participate. To ensure respondents' confidentiality, their names were excluded from the questionnaire, and the anonymity of the respondents was maintained.

Ethics approval and consent to participate Ethical clearance was obtained from the Salale University Ethical Review Committee (Ref. No. SLUERC/32/2019, on March 18/2019). Written permission was obtained from the North Shewa Zone Health Bureau (NSZHB), and written informed consent was obtained from each respondent. The respondents were informed that their inclusion in the study was voluntary, and that they were free to withdraw from the study if they were not willing to participate. To ensure respondent confidentiality, their names were excluded from the questionnaire, and their anonymity was maintained.

Consent for publication Not applicable.

\section{References}

Anderson LM, Scrimshaw SC, Fullilove MT, Fielding JE, Normand J, and Task Force on Community Preventive Services (2003) Culturally competent healthcare systems: a systematic review. Am J Prev Med 24(3):68-79

Berhe H, Berhe H, Bayray A, Godifay H, Beedemariam G (2017) Status of caring, respectful and compassionate health care practice in Tigrai regional state: patients' perspective. Int J Caring Sci 10(3):1119

Berwick DM (2009) What 'patient-centered' should mean: confessions of an extremist. Health Aff 28(Supplement 1):w555-w565. https://doi. org/10.1377/hlthaff.28.4.w555

Blanco MA, Maderer A, Price LL, Epstein SK, Summergrad P (2013) Efficiency is not enough; you have to prove that you care: role modelling of compassionate care in an innovative resident-asteacher initiative. Educ Health 26(1):60

Bluth K, Blanton PW (2015) The influence of self-compassion on emotional well-being among early and older adolescent males and females. J Posit Psychol 10(3):219-230

Boal KB, Schultz PL (2007) Storytelling, time, and evolution: the role of strategic leadership in complex adaptive systems. Leadersh Q 18(4): $411-428$

Chapin HL, Darnall BD, Seppala EM, Doty JR, Hah JM, Mackey SC (2014) Pilot study of a compassion meditation intervention in chronic pain. J Compassionate Health Care 1(1):1-12

Chochinov HM (2007) Dignity and the essence of medicine: the a, B, C, and D of dignity conserving care. BMJ 335(7612):184-187

Davis D, O'Brien MAT, Freemantle N, Wolf FM, Mazmanian P, TaylorVaisey A (1999) Impact of formal continuing medical education: do conferences, workshops, rounds, and other traditional continuing education activities change physician behavior or health care outcomes? Jama 282(9):867-874

Davis L (2013) Dignity Health: Dignity Health survey finds majority of Americans rate kindness as top factor in quality health care.: [http:// www.reuters.com/article/2013/11/13/ca-dignity-healthidUSnBw135348a+100+BSW20131113]

De Silva D (2014) Helping measure person-centred care: Health Foundation

Dewar B, Adamson E, Smith S, Surfleet J, King L (2014) Clarifying misconceptions about compassionate care. J Adv Nurs 70(8): $1738-1747$
Dyrbye LN, Shanafelt TD (2011) Physician burnout: a potential threat to successful health care reform. Jama 305(19):2009-2010. https://doi. org/10.1001/jama.2011.652

Epstein RM, Fiscella K, Lesser CS, Stange KC (2010) Why the nation needs a policy push on patient-centered health care. Health Aff 29(8):1489-1495. https://doi.org/10.1377/hlthaff.2009.0888

Gallagher A, Li S, Wainwright P, Jones IR, Lee D (2008) Dignity in the care of older people-a review of the theoretical and empirical literature. BMC Nurs 7(1):11

Gilbert JA, Carr-Ruffino N, Ivancevich JM, Konopaske R (2012) Toxic versus cooperative behaviors at work: the role of organizational culture and leadership in creating community-centered organizations. Int J Leadership Stud 7(1):29-47

Goodrich J (2016) What makes a compassionate relationship between caregiver and patient? Findings from the 'anniversary'Schwartz rounds. J Compassionate Health Care 3(1):1-8

Graber DR, Mitcham MD, Coker-Bolt P, Wise HH, Jacques P, Edlund B, Annan-Coultas D (2012) The caring professionals program: educational approaches that integrate caring attitudes and empathic behaviors into health professions education. J Allied Health 41(2):90-96

Haslam D (2015) More than kindness. J Compassionate Health Care 2(1): $1-3$

Kahn KF (1992) Does being male help? An investigation of the effects of candidate gender and campaign coverage on evaluations of US senate candidates. J Polit 54(2):497-517

Kleinman A, Eisenberg L, Good B (1978) Culture, illness, and care: clinical lessons from anthropologic and cross-cultural research. Ann Intern Med 88(2):251-258

Larson M (2014) Cultural immersion and compassionate care in a study abroad course: the Greek connection. J Compassionate Health Care $1(1): 1-3$

Larson RW (2000) Toward a psychology of positive youth development. Am Psychol 55(1):170

Limebury J, Shea S (2015) The role of compassion and 'Tough Love' in caring for and supporting the homeless: experiences from 'Catching Lives' Canterbury UK. J Compassionate Health Care 2(1):7

Lown BA, Rosen J, Marttila J (2011) An agenda for improving compassionate care: a survey shows about half of patients say such care is missing. Health Aff 30(9):1772-1778

Maslach C, Jackson SE, Leiter MP, Schaufeli WB, Schwab RL (1986) Maslach burnout inventory, vol 21. Consulting Psychologists Press, Palo Alto, pp 3463-3464

Mechili EA, Angelaki A, Petelos E, Sifaki-Pistolla D, Chatzea VE, Dowrick C, Dückers M (2018) Compassionate care provision: an immense need during the refugee crisis: lessons learned from a European capacity-building project. J Compassionate Health Care $5(1): 2$

Pommier EA (2010) The Compassion Scale: The University of Texas At Austin

Reis V, Deller B, Catherine Carr C, Smith J (2012) Respectful maternity care. USAID, Washington DC

Shea S, Lionis C (2014) Introducing the journal of compassionate health care: Springer

Shea S, Wynyard R, Lionis C (2014) Providing compassionate healthcare: challenges in policy and practice: Routledge

Sinclair S, Hack TF, Raffin-Bouchal S, McClement S, Stajduhar K, Singh P, Chochinov HM (2018) What are healthcare providers' understandings and experiences of compassion? The healthcare compassion model: a grounded theory study of healthcare providers in Canada. BMJ Open 8(3):e019701

Stewart MA (1995) Effective physician-patient communication and health outcomes: a review. CMAJ: Can Med Assoc J 152(9):1423

Tiruneh MA, Ayele BT, Beyene KGM (2019) Knowledge of, and attitudes toward, codes of ethics and associated factors among medical doctors in Addis Ababa, Ethiopia. Medicolegal Bioethics 9:1-10 
Wamisho BL, Abeje M, Feleke Y, Hiruy A, Getachew Y (2015) Analysis of medical malpractice clams and measures proposed by the health professionals ethics federal committee of Ethiopia: review of the three years proceedings. Ethiop Med J 53(Suppl 1):1-6

Wamisho BL, Tiruneh MA, Teklemariam LE (2019) Surgical and medical error claims in Ethiopia: trends observed from 125 decisions made by the federal ethics committee for health professionals ethics review. Medicolegal Bioethics 9:23-31

Wise CG, Alexander JA, Green LA, Cohen GR, Koster CR (2011) Journey toward a patient-centered medical home: readiness for change in primary care practices. Milbank Quart 89(3):399-424. https://doi.org/10.1111/j.1468-0009.2011.00634.x

Zimmermann C, Del Piccolo L, Finset A (2007) Cues and concerns by patients in medical consultations: a literature review. Psychol Bull 133(3):438

Publisher's note Springer Nature remains neutral with regard to jurisdictional claims in published maps and institutional affiliations. 